Fourth International Conference on Sustainable Construction Materials and Technologies http://www.claisse.info/Proceedings.htm

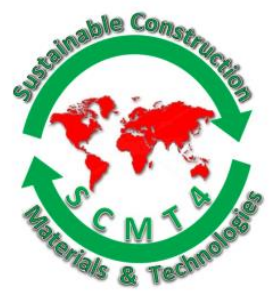

SCMT4

Las Vegas, USA, August 7-11, 2016

\title{
The Effect of Corrosion Patch Geometry on Stress Intensity Factors for External Surface Cracks in Cast Iron Water Mains
}

\author{
Chamal Randeniya ${ }^{1 \mathrm{a}}$, D.J.Robert*1b, Guoyang Fu' ${ }^{1 \mathrm{c}}$, and Chun-Qing Li ${ }^{1 \mathrm{~d}^{*}}$ \\ Civil, Environmental and Chemical Engineering, School of Engineering, RMIT University, GPO. Box \\ 2476, Melbourne Central, Vic 3001, Australia. ${ }^{1 a}$ Email: 〈s3511732@student.rmit.edu.au〉, \\ ${ }^{*}{ }^{*}$ Email: <dilan.robert@rmit.edu.au>, ${ }^{1 c}$ Email: 〈guoyang.fu@rmit.edu.au>, \\ ${ }^{1 d}$ Email: <chunqing.li@rmit.edu.au>.
}

\begin{abstract}
Stress intensity factors play a vital role in predicting the failures of cast iron water mains which are being utilised as buried water pipes worldwide since several decades. The corrosion patterns which can vary from uniform, pitting and/or patch, may result uneven pipe thickness affecting the prediction of stress intensity factors. An inaccurate prediction of stress intensity of the corroded pipes can mislead condition assessments/failure predictions of buried pipes, resulting severe socio-economic losses due to unexpected failures. The objective of this paper is to study the effect of external corrosion geometry on stress intensity factors for external surface cracks in cast iron water mains using finite element (FE) modelling. In this study, spherical patch geometry is adopted using a 3-D FE model to characterise external corrosion of buried pipes. Results from the study revealed that corrosion geometry has a significant effect on the stress intensity induced due to external surface cracks. The findings can be used to evaluate the variation of stress intensity factor of external surface cracks with variation of corrosion geometry.
\end{abstract}

\section{INTRODUCTION}

Pipelines are essential infrastructures in the current economy and modern society as they are the most economical and safest way of distributing various service needs (Water, gas, oil etc.). The vital role that they play in the world's economy is reflected in the many kilometres of pipelines laid worldwide. The ever increasing needs of socio-economic aspects demand more use of pipelines and they have grown rapidly in the past few decades. Various materials have been used for manufacturing pipes such as cast iron, steel, vitrified clay and concrete (Li \& Yang 2012). The majority of the pipes were made of cast iron in the past few decades and a significant portion of these cast iron pipes are still functioning in current pipeline networks (Rajani \& Kleiner 2001).

Structural failures of pipes can cause significant consequences in terms of economic loss, public safety and performance of the utility. Most of buried pipes are usually affected by internal and external corrosion (Li \& Mahmoodian 2013) and corrosion of pipes can manifest in various forms such as uniform, patch and pitting (Rajeev et al. 2014). The pits induced by corrosion are often considered as precursors to pipe cracks, which can grow and lead to structural failures (Yang, Li \& Yang 2016). Stress intensity factor 
$\left(\mathrm{K}_{\mathrm{I}}\right)$ is used to quantify the stress intensity caused by cracks. Extensive research work has been carried out to determine the stress intensity factors for internal and external surface cracks in pipes (Diamantoudis \& Labeas 2005; Li \& Yang 2012; Moulick \& Sahu 2012; Predan, Močilnik \& Gubeljak 2013; Raju \& Newman 1982; Saffih \& Hariri 2006; Yang, Li \& Yang 2016). Most of such research work assumes cracks on cylindrical pipes are semi-elliptical in shape (Diamantoudis \& Labeas 2005). Error! Reference source not found. shows a schematic of the geometry of an external surface crack on a pipe.

Various studies have been carried out to evaluate stress intensity factor for internal and external surface cracks. Most studies used Finite element (FE) methods to evaluate stress intensity factors (Diamantoudis \& Labeas 2005; Li \& Yang 2012; Predan, Močilnik \& Gubeljak 2013) while some used analytical methods (Moulick \& Sahu 2012; Yang, Li \& Yang 2016). Raju and Newman (1982) calculated the influence coefficients of stress intensity factors for semi-elliptical surface cracks (internal and external) for various aspect ratios using FE analysis. With these influence coefficients, the stress intensity factor can be calculated for a wide range of surface crack geometries. Li and Yang (2012) determined the influence coefficients for internal surface cracks with high aspect ratios. All these studies were only considered the existence of surface cracks, without devoting much attention on pipe wall thickness variation due to corrosion, leading to limited practical applications. Furthermore, several research works has been conducted to study the stress concentration and crack initiation due to pipe corrosion ( $\mathrm{Ji}$ et al. 2015; Kim \& Son 2004; Zhang et al. 2013). However, the research work which investigates the effect of corrosion pit geometry on the fracture behaviour of cracks is limited.

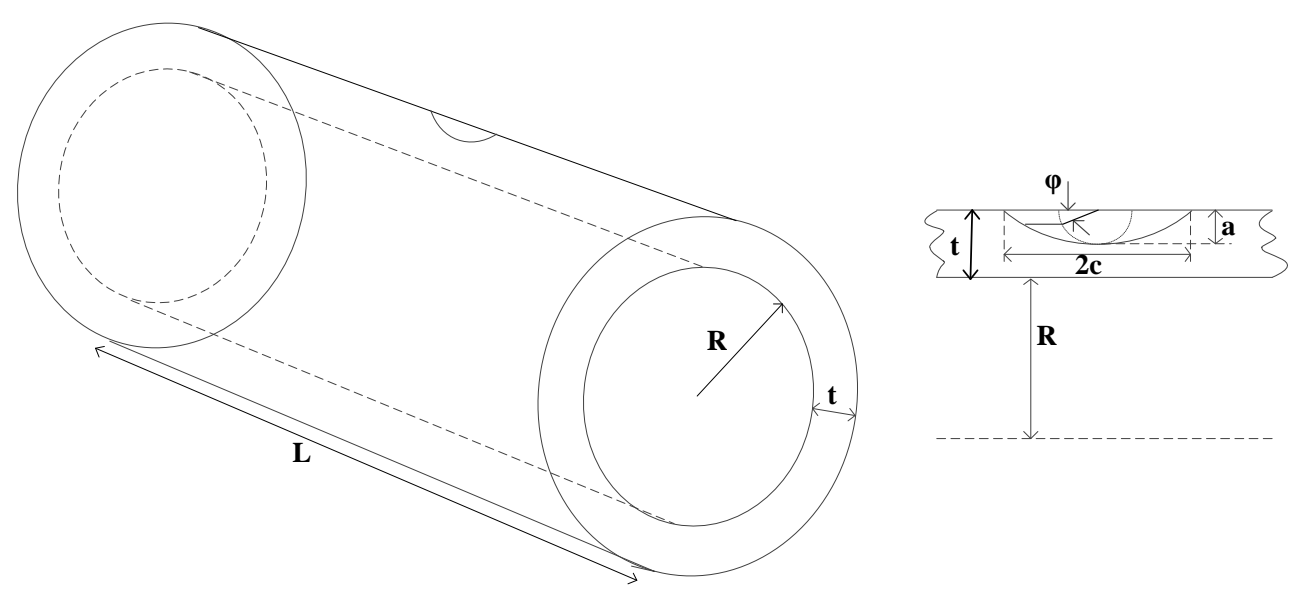

Figure 1. Semi-elliptical external surface crack in a pipe

This paper aims to investigate the effect of corrosion geometry on the stress intensity factors for external surface cracks in cast iron pipes. A three dimensional finite element model (3-D FE) is employed in this study to evaluate the stress intensity factors for a crack on a corroded pipe surface. Corrosion geometry is considered as patch corrosion with a spherical surface for the simplicity of the model. Firstly, the developed 3D FE models are validated by comparing the results with published data. Then the validated models are employed to evaluate stress intensity factors of cracks in pipes with various corrosion geometries.

\section{FAILURE CRITERIA FOR CAST IRON PIPES}

Failure of a cast iron pipe can be characterised by fracture as it is a brittle material. In standard designs (BS 7910 2005; API RP 1102 2007)the failure of pipes are identified by comparing the intensified stress 
field at sharp cracks against the fracture toughness of the materials $\left(\mathrm{K}_{\mathrm{c}}\right)$. According to the fundamental principles of fracture mechanics, stress field ahead of a sharp crack (or flaw) in a structural member (pipe wall) can be described and measured by a single parameter, $K$, which is known as the Stress intensity factor (Barsom \& Rolfe 1999). The failure of the pipe can be defined when this stress intensity factor exceeds the fracture toughness of the material $\left(\mathrm{K}>\mathrm{K}_{\mathrm{c}}\right)$. Fracture toughness of cast iron material can be 10 - $20 \mathrm{MN} / \mathrm{m}^{1.5}$ (AS 1830-2007 2007).

Stress intensity factor $(K)$ is related to nominal stress level $(\sigma)$, size of the crack $(a)$, shape and orientation of the crack, and dimensions of the structural member which crack occurs. The general relationship of the stress intensity factor is shown below (Hertzberg 1996),

$$
K=\sigma \sqrt{\pi \cdot a} f(\phi)
$$

Where $\varphi$ is measured as shown in Error! Reference source not found. which define the position of the crack front and $f(\varphi)$ is the correction factor, which is a function of crack geometries and structural element geometries. Depending on the relative movements of two crack surfaces there are three modes of fracture which are required to define exact expressions for the stress intensity factors. Those three modes are (Barsom \& Rolfe 1999): (i) opening mode - Mode I ( $\left.\mathrm{K}_{\mathrm{I}}\right)$; (ii) in-plane shear mode - Mode II ( $\mathrm{K}_{\mathrm{II}}$ ); (iii) out of plane shear or tear mode - Mode III $\left(\mathrm{K}_{\mathrm{III}}\right)$. In this study only Mode I is considered as it is found to be the dominant cracking condition under normal service conditions (Li \& Yang 2012).

\section{THREE-DIMENSIONAL FINITE ELEMENT MODELLING}

Three dimensional FE analyses were conducted in this study using ABAQUS (ABAQUS Inc. 2011) to obtain the stress intensity factors of pipes having patch corrosion with semi-elliptical surface cracks.

Figure 2 shows a detail geometry idealization of a surface crack on a corroded pipe surface which was simplified to a spherical surface in the current study with a radius of $R_{p}$ and a depth of $a_{p}$. The pipe length is selected to satisfy $\mathrm{L} / \mathrm{c}>20$ in order to minimize the length effect on the stress intensity factor. The behaviour of cast iron material has been modelled as elastic material, in which Young's modulus and Poisson's ratio are assumed as $113 \mathrm{GPa}$ and 0.3 respectively. The pipe, which was fixed at the base, has been applied with an internal water pressure of 0.6MPa during all the analysis (Figure 3).

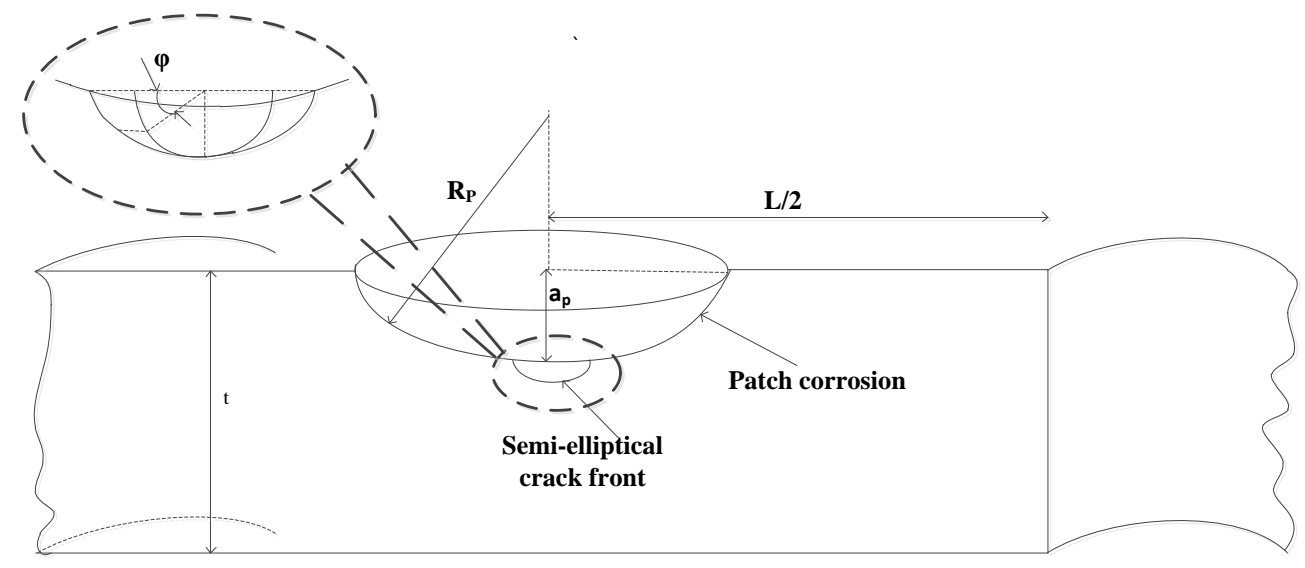

Figure 2. External surface crack on a corroded pipe surface 
There are two approaches to evaluate the stress intensity factors numerically: the displacement based and energy based methods. The displacement based method requires very fine mesh as results depend on the displacements obtained from the analysis ( $\mathrm{Li} \&$ Yang 2012). Therefore, the energy based method is employed in many research works to calculate the stress intensity factor numerically(Li \& Yang 2012).

In this study, the contour integral method available in ABAQUS (ABAQUS Inc. 2011) was used to determine $K_{I}$ values based on the energy method. In the FE model, 20-node quadratic brick elements with reduced integration (C3D20R) were employed to represent the pipe in the contour integral regions. However $1^{\text {st }}$ contour integral region which surrounds the crack line is modelled using wedge elements (15-node quadratic triangular prism elements - C3D15) as shown in

Figure 4. The square-root of the modelled by shifting the mid-poin Other regions of the pipe are $\mathrm{m}$ minimize the model size and redı adopted mesh discretisation of the Figure 5.

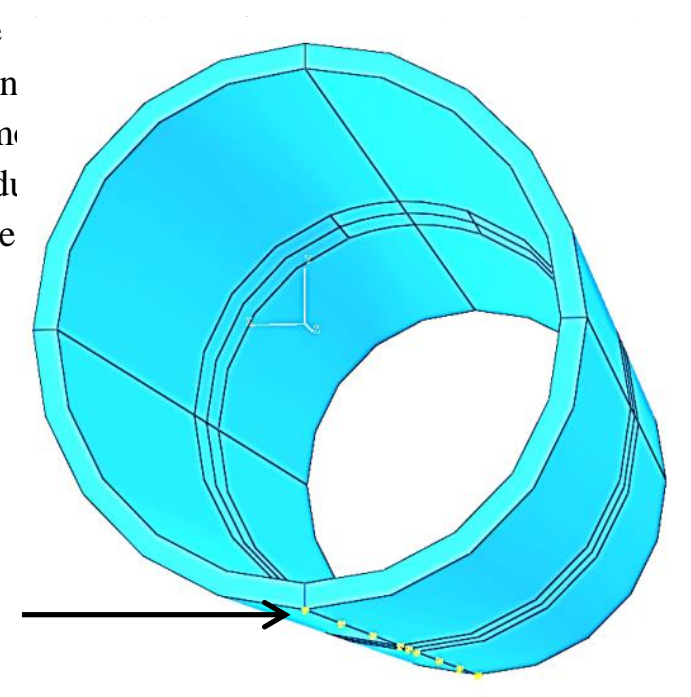

i-elliptical crack front is : node parameter $=0.25$ ) . lements appropriately to uracy of the results. The

Bottom line of the pipe

\section{Figure 3. Boundary conditions of the pipe}

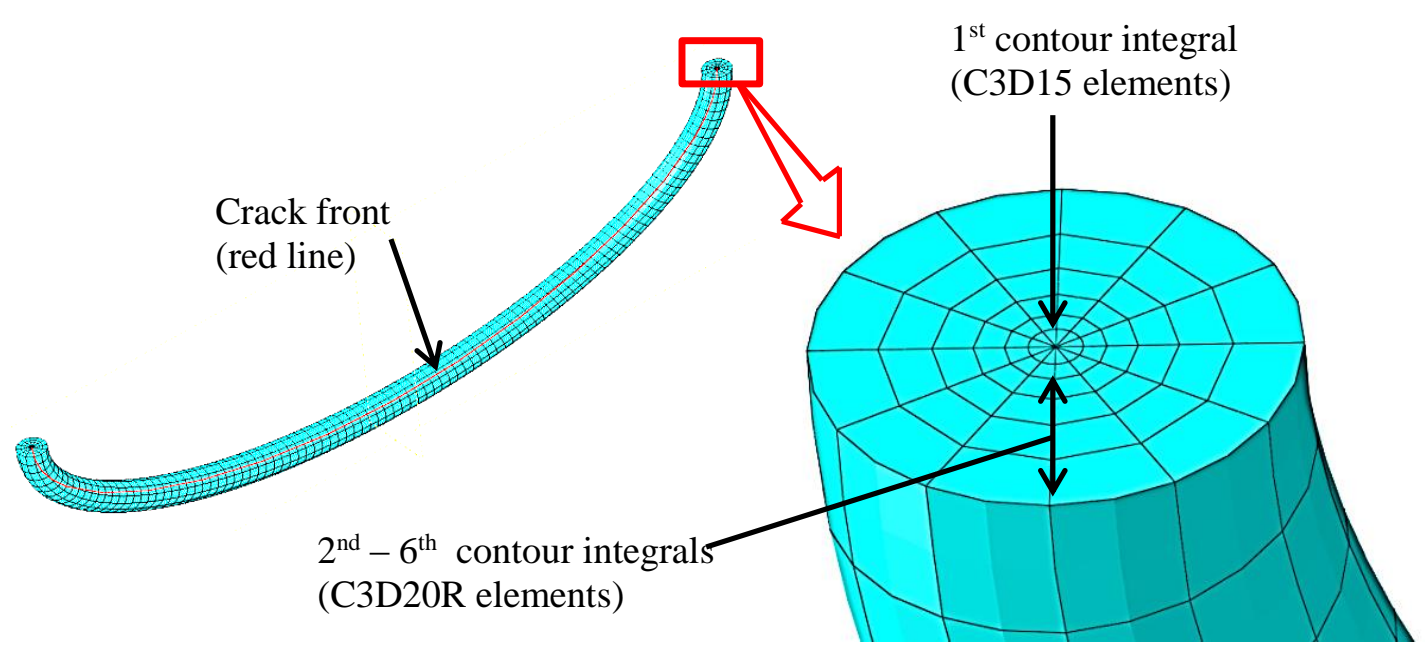




\section{Figure 4. Mesh discretization and contour integrals around crack line}

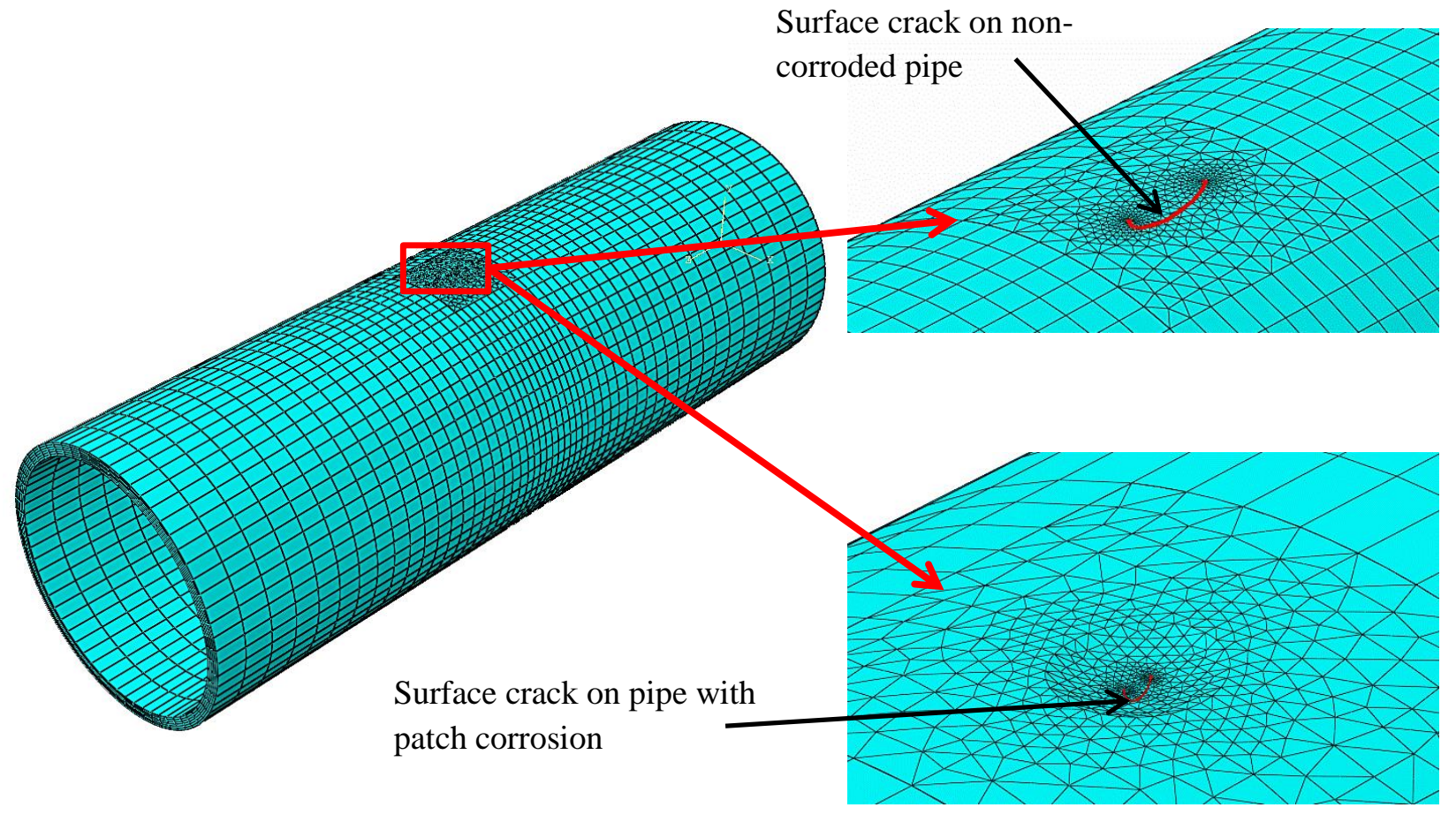

Figure 5. Mesh discretization in corroded and non-corroded pipe surface

\section{Validation of the FE model}

A pipe with internal radius $R$, wall thickness $t$, and length $L$ containing a semi-elliptical surface crack of length $2 c$, and depth $a$ on the outer surface of the pipe (Error! Reference source not found.) was used for validating the FE model against the data published by Raju and Newman (1982) who proposed an analytical model to predict stress intensity factor of an external surface crack in a pressurised pipe. No experimental data is available in literature on stress intensity factor for surface cracks of corroded pipes.

Stress intensity factor for an external surface crack in a pressurised pipe has been proposed as (Raju \& Newman Jr 1979):

$$
K_{I}=\frac{P \cdot R}{t} \sqrt{\pi \frac{a}{Q}} F_{e}\left(\frac{a}{c}, \frac{a}{t}, \frac{t}{R}, \phi\right)
$$

where $P$ is the internal pressure, $R$ is the internal radius of the pipe, $t$ is the pipe thickness, $a$ is the depth of surface crack, $Q$ is the shape factor for elliptical crack and $F_{e}$ is the boundary correction factor for external surface crack. $\mathrm{F}_{\mathrm{e}}$ can be determined from:

$$
F_{e}=\frac{t}{R}\left(\frac{R^{2}}{R_{o}^{2}-R^{2}}\right)\left[2 G_{0}+2\left(\frac{a}{R_{o}}\right) G_{1}+3\left(\frac{a}{R_{o}}\right)^{2} G_{2}+4\left(\frac{a}{R_{o}}\right)^{3} G_{3}\right]
$$


where $R_{o}$ is the outer radius of the pipe and $G_{j}(j=0,1,2,3)$ are the influence coefficients for the $j^{\text {th }}$ stress distribution on crack surface which can be obtained from finite element analysis, as discussed by Raju and Newman (1982). Correction factor for semi elliptical cracks, $Q$ can be determined from:

$Q=1+1.464\left(\frac{a}{c}\right)^{1.65}$

The influence coefficients $\left(\mathrm{G}_{\mathrm{j}}\right)$ for pipes with semi-elliptical internal and external surface cracks were derived using FE analysis in the original model development (Raju and Newman (1982). These influence coefficients were derived on the basis of four basic load distributions as uniform, linear, quadratic and cubic across the crack surface. For comparison purposes, $a / c$ ratios of 0.4 and $1, a / t$ ratios of 0.2 and 0.5 and $t / R$ ratio of 0.1 are considered as shown in Table 1 . In order to validate the FE model in the current study, $F_{e}$ values were compared using Eq. 2 with $K_{I}$ obtained from current study, and using Eq. 3 which was proposed by Raju and Newman (1982). The results revealed that output from current study are in good agreement $(<5 \%$ difference) with the results reported in literature, thus the developed model could be used to predict the stress intensity of external surface cracks with high reliability.

Table 1. Comparison of boundary-correction factor $\left(F_{e}\right)$ between FEM and data published in Raju and Newman (1982) for external surface cracks $(t / R=0.1)$

\begin{tabular}{|c|c|r|r|r|r|r|r|}
\hline $\mathrm{a} / \mathrm{c}$ & $\begin{array}{c}\text { angle } \\
(\varphi)\end{array}$ & \multicolumn{3}{|c|}{$\mathrm{a} / \mathrm{t}=0.2$} & \multicolumn{3}{|c|}{$\mathrm{a} / \mathrm{t}=0.5$} \\
\cline { 3 - 8 } & & FEM & $\begin{array}{c}\text { Raju and } \\
\text { Newman (1982) }\end{array}$ & $\begin{array}{c}\text { Difference } \\
(\%)\end{array}$ & FEM & $\begin{array}{c}\text { Raju and } \\
\text { Newman (1982) }\end{array}$ & $\begin{array}{c}\text { Difference } \\
(\%)\end{array}$ \\
\hline 0.4 & 0 & 0.784 & 0.753 & 4.17 & 0.991 & 0.946 & 4.77 \\
\cline { 2 - 8 } & $\pi / 8$ & 0.820 & 0.788 & 4.09 & 1.004 & 0.968 & 3.73 \\
\cline { 2 - 8 } & $\pi / 4$ & 0.958 & 0.920 & 4.13 & 1.163 & 1.115 & 4.29 \\
\cline { 2 - 8 } & $3 \pi / 8$ & 1.060 & 1.021 & 3.76 & 1.281 & 1.238 & 3.50 \\
\cline { 2 - 8 } & $\pi / 2$ & 1.094 & 1.056 & 3.66 & 1.324 & 1.282 & 3.25 \\
\hline \multirow{2}{*}{1} & 0 & 1.158 & 1.104 & 4.89 & 1.275 & 1.216 & 4.82 \\
\cline { 2 - 8 } & $\pi / 8$ & 1.081 & 1.037 & 4.30 & 1.178 & 1.127 & 4.51 \\
\cline { 2 - 8 } & $\pi / 4$ & 1.045 & 1.004 & 4.05 & 1.120 & 1.079 & 3.78 \\
\cline { 2 - 8 } & $3 \pi / 8$ & 1.030 & 0.992 & 3.81 & 1.094 & 1.063 & 2.89 \\
\cline { 2 - 8 } & $\pi / 2$ & 1.026 & 0.989 & 3.74 & 1.086 & 1.060 & 2.41 \\
\hline
\end{tabular}

\section{RESULTS - PARAMETRIC STUDY}

Having validated the modelling methodology, a series of FE analyses was conducted considering a semielliptical surface crack in longitudinal direction, with a/c and a/t ratios of 1 and 0.2 respectively. Further $a_{p} / t$ ratios of 0.2 and 0.5 were considered and, $a_{p} / R_{p}$ ratios of $0.05,0.075$ and 0.1 were used to define various corrosion patch geometries. $R_{p} / R$ was varied from $0.2-1$ with $R / t=0.1$ in the current analysis. 
Table 2 shows the results of $\mathrm{FE}$ analysis obtained as a variation of $\mathrm{F}_{\mathrm{e}}$ with various corrosion patch geometry for $\mathrm{a}_{\mathrm{p}} / \mathrm{t}$ of 0.2 . Results reveal a slight increase in $\mathrm{F}_{\mathrm{e}}$ (i.e. stress intensity) with the increase in corrosion patch radius, while a substantial reduction of $F_{e}$ is obtained at the lowest position of the crack (where $\varphi=\pi / 2$ ). This can be due to the stress variation along the crack surface. Hence, the results reveal that the stress intensity factors can be functions of stresses around crack front and other associated crack geometries as aforementioned.

Table 2. Variation of $F_{e}$ with corrosion patch radius $\left(a_{p} / t=0.2\right)$

\begin{tabular}{|l|r|r|r|r|}
\hline \multirow{2}{*}{ angle $(\varphi)$} & \multicolumn{4}{|c|}{$\mathrm{Rp}$} \\
\cline { 2 - 5 } & $30 \mathrm{~mm}$ & $40 \mathrm{~mm}$ & $60 \mathrm{~mm}$ & $150 \mathrm{~mm}$ \\
\hline 0 & 1.599 & 1.647 & 1.667 & 1.719 \\
\hline$\pi / 8$ & 1.506 & 1.532 & 1.553 & 1.623 \\
\hline$\pi / 4$ & 1.418 & 1.440 & 1.463 & 1.530 \\
\hline $3 \pi / 8$ & 1.370 & 1.391 & 1.415 & 1.480 \\
\hline$\pi / 2$ & 1.355 & 1.375 & 1.400 & 1.464 \\
\hline
\end{tabular}

Results also revealed that the stress intensity factor decreases with the increase of $a_{p} / R_{p}$ ratio as showed in Figure 6. However this variation is less for lower $a_{p} / t$ ratio compared to the higher $a_{p} / t$ ratios. This is because; higher the $a_{\mathrm{p}} / \mathrm{t}$ reveals lower remaining wall thicknesses, which in turn results higher stress increases due to applied loadings.

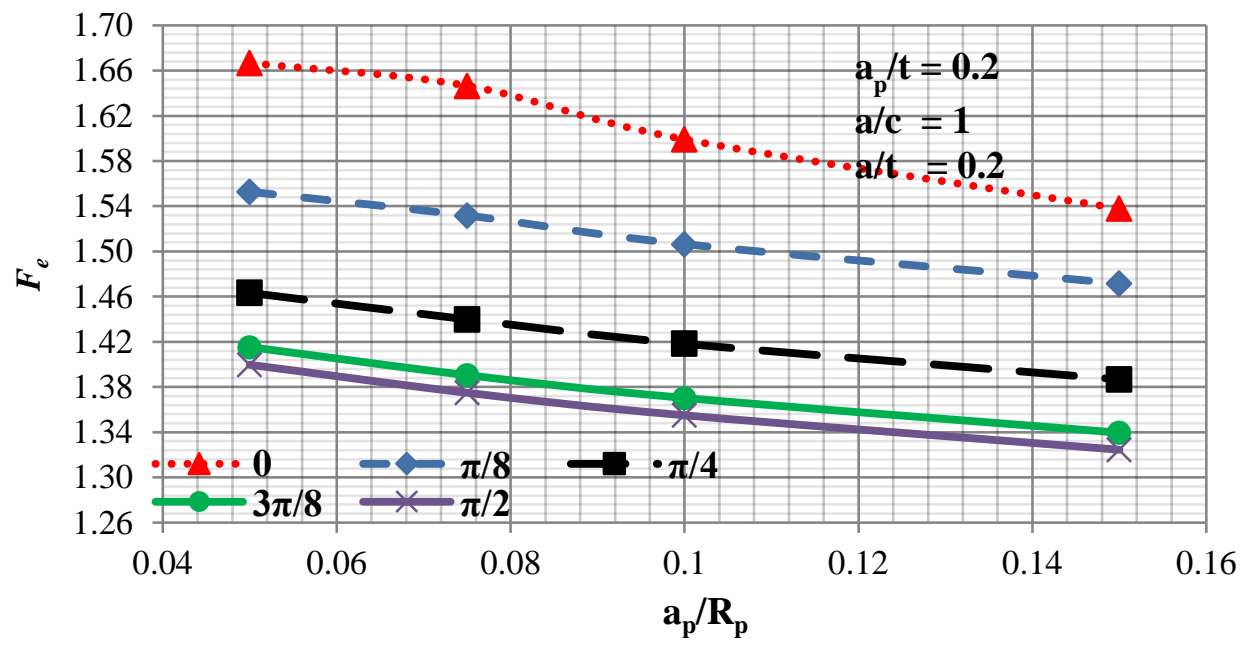

(a)

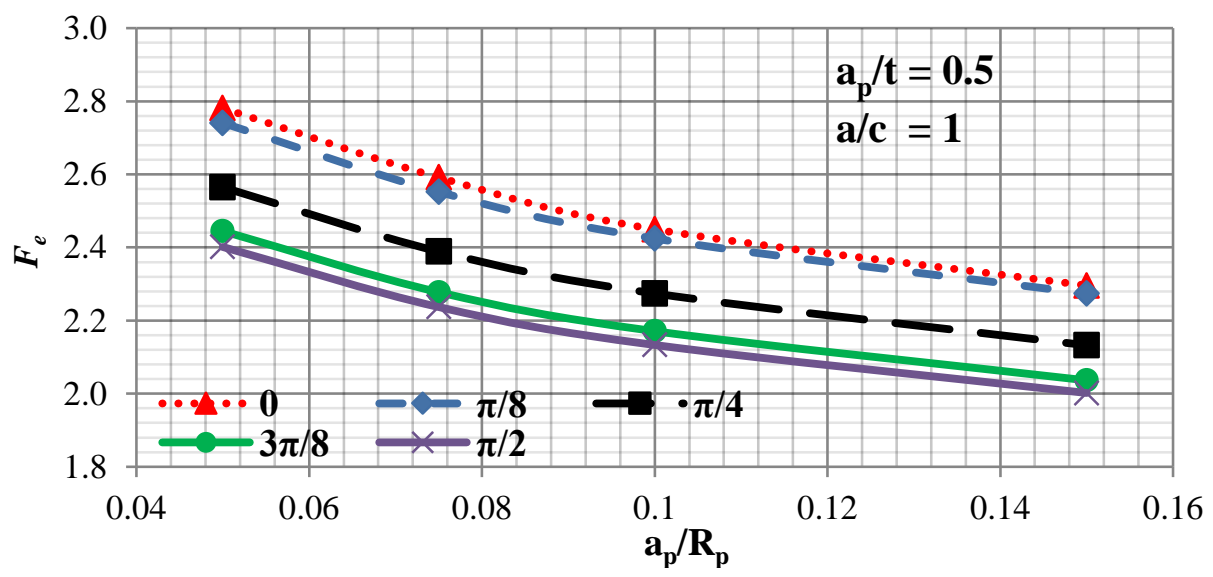


(b)

Figure 6. Variation of $F_{e}$ with $a_{p} / R_{p}$ ratio : (a) $a_{p} / t=0.2$ (b) $a p / t=0.5$

Table 3. Fe values for various corrosion patch geometries $(a / c=1, a / t=0.2, t / R=0.1)$

\begin{tabular}{|c|c|r|r|r|r|}
\hline \multirow{3}{*}{$\mathrm{a}_{\mathrm{p}} / \mathrm{t}$} & angle $(\varphi)$ & \multicolumn{4}{|c|}{$\mathrm{a}_{\mathrm{p}} / \mathrm{R}_{\mathrm{p}}$} \\
\cline { 2 - 6 } & & 0.05 & 0.075 & 0.1 & 0.15 \\
\hline \multirow{3}{*}{0.2} & 0 & 1.667 & 1.647 & 1.599 & 1.538 \\
\cline { 2 - 6 } & $\pi / 8$ & 1.553 & 1.532 & 1.506 & 1.472 \\
\cline { 2 - 6 } & $\pi / 4$ & 1.463 & 1.440 & 1.418 & 1.387 \\
\cline { 2 - 6 } & $3 \pi / 8$ & 1.415 & 1.391 & 1.370 & 1.340 \\
\cline { 2 - 6 } & $\pi / 2$ & 1.400 & 1.375 & 1.355 & 1.325 \\
\hline 0.5 & 0 & 2.781 & 2.592 & 2.450 & 2.296 \\
\cline { 2 - 6 } & $\pi / 8$ & 2.741 & 2.552 & 2.424 & 2.274 \\
\cline { 2 - 6 } & $\pi / 4$ & 2.565 & 2.389 & 2.274 & 2.132 \\
\cline { 2 - 6 } & $3 \pi / 8$ & 2.445 & 2.278 & 2.171 & 2.036 \\
\cline { 2 - 6 } & $\pi / 2$ & 2.401 & 2.237 & 2.133 & 2.002 \\
\hline
\end{tabular}

The results of the parametric study are further summarised in Table 3 in terms of stress intensity factors for a semi-elliptical surface crack on a corroded pipe surface. Such results can be helpful for condition assessment of the pipes having surface cracks in corroded patches. It should be noted that the results from the current study is limited to the corrosion geometries considered in the present study. The application of the results of current study is explained using the following example.

Example case: Consider a cast iron water main (Diameter $=200 \mathrm{~mm}$, wall thickness $=10 \mathrm{~mm})$ subjecting to a $2 \mathrm{MPa}$ maximum water pressure due to estimated water hammer effect. The pipe is corroded with two large corrosion patches which can be simplified as having spherical surfaces with radius of $50 \mathrm{~mm}$ and $100 \mathrm{~mm}$ and a depth of $5 \mathrm{~mm}\left(\mathrm{a}_{\mathrm{p}}\right)$. If the patches contain cracks of $\mathrm{a}=2 \mathrm{~mm}$ and $\mathrm{c}=2 \mathrm{~mm}$, which corrosion pit will have the lower Factor of Safety (FoS) against failure?

By using Equation 2 and data in

Table 3, the $\mathrm{K}_{\mathrm{I}}$ values can be calculated as 4.95 and $5.62 \mathrm{MN} / \mathrm{m}^{1.5}$ for $50 \mathrm{~mm}$ and $100 \mathrm{~mm}$ radius patches respectively. If the Fracture toughness of the pipe material $\left(\mathrm{K}_{\mathrm{c}}\right)$ is $10 \mathrm{MN} / \mathrm{m}^{1.5}$, Factor of safety of the corroded patches can be estimated as 2.0 and 1.8 respectively. For the considered case, the pipe can be classified as 'safe' under both the patch geometries, however larger radius of patch surface indicates lower FoS against failure by facture.

\section{DISCUSSION}

In this study, the effect of external corrosion geometry on stress intensity factors for external surface cracks in cast iron water mains has been evaluated with the use of 3D FE analyses. Firstly, the FE models are verified using reported analytical data, and then the stress intensity factors for a surface crack 
embedded in corroded pipe surface with various corrosion geometries are determined. It has been found that variation of stress intensity factor due to the variation of corrosion patch radius $(30-150 \mathrm{~mm})$ is about $8-12 \%$. Further, a decreasing and increasing trends of $F_{e}$ was identified with increasing $a_{p} / R_{p}$ ratio and increasing $a_{p} / t$ ratio respectively. Typical values of $F_{e}$ are presented to calculate stress intensity factor for surfaced cracks on a corroded pipe surface within considered crack geometries. The findings from this study can be used to study the behaviour of stress intensity factor with changing corrosion geometry. This research work is currently being extended to develop a closed form equation to predict the stress intensity factor under various corrosion geometries.

\section{ACKNOWLEDGEMENTS}

Financial support from Australian Research Council under DP140101547 and LP150100413 is gratefully acknowledged.

\section{REFERENCES}

ABAQUS Inc. 2011, 'ABAQUS V.6.11 User's Manual', Providence, Rhode Island.

API RP 1102, 2007, Steel Pipelines Crossing Railroads and Highways, American Petrolium Institute, Washington, D.C. 20005.

AS 1830-2007, 2007, Australian standard-Grey cast iron, Standards Australia, Sydney, NSW 2001, Australia.

Barsom, JM \& Rolfe, ST 1999, Fracture and Fatigue Control in Structures - Applications of Fracture Mechanics: (MNL 41), Third edition edn, ASTM International, 978-0-8031-2082-2, $<$ http://app.knovel.com/hotlink/toc/id:kpFFCSAFM1/fracture-fatigue-control/fracture-fatiguecontrol>.

$B S$ 7910, 2005, Guide to methods for assessing the acceptability of flaws in metallic structure, British Standard.

Diamantoudis, AT \& Labeas, GN 2005, 'Stress intensity factors of semi-elliptical surface cracks in pressure vessels by global-local finite element methodology', Engineering Fracture Mechanics, vol. 72, no. 9, pp. 1299-312.

Hertzberg, RW 1996, Deformation and Fracture Mechanics of Engineering Materials. 4th ed., John Wiley and Sons.

Ji, J, Zhang, C, Kodikara, J \& Yang, S-Q 2015, 'Prediction of stress concentration factor of corrosion pits on buried pipes by least squares support vector machine', Engineering Failure Analysis, vol. 55, pp. $131-8$.

Kim, Y-J \& Son, B-G 2004, 'Finite element based stress concentration factors for pipes with local wall thinning', International Journal of Pressure Vessels and Piping, vol. 81, no. 12, pp. 897-906.

Li, CQ \& Mahmoodian, M 2013, 'Risk based service life prediction of underground cast iron pipes subjected to corrosion', Reliability Engineering \& System Safety, vol. 119, pp. 102-8. 
Li, CQ \& Yang, ST 2012, 'Stress intensity factors for high aspect ratio semi-elliptical internal surface cracks in pipes', International Journal of Pressure Vessels and Piping, vol. 96-97, pp. 13-23.

Moulick, SK \& Sahu, YK 2012, 'Stress Intensity Factor for Cracks in Thick Pressure Vessels using Weight Function Technique', paper presented to IJCA Proceedings on National Conference on Innovative Paradigms in Engineering and Technology (NCIPET 2012).

Predan, J, Močilnik, V \& Gubeljak, N 2013, 'Stress intensity factors for circumferential semi-elliptical surface cracks in a hollow cylinder subjected to pure torsion', Engineering Fracture Mechanics, vol. 105 , pp. 152-68.

Rajani, B \& Kleiner, Y 2001, 'Comprehensive review of structural deterioration of water mains: Physically based models', Urban Water, vol. 3, no. 3, pp. 151-64.

Rajeev, P, Kodikara, J, Robert, D, Zeman, P \& Rajani, B 2014, Factors contributing to large diameter water pipe failure as evident from failure inspection, 2013, <http://hdl.handle.net/1959.3/375347>.

Raju, IS \& Newman, JJC 1982, 'Stress-Intensity Factors for Internal and External Surface Cracks in Cylindrical Vessels', Journal of Pressure Vessel Technology, vol. 104, no. 4, pp. 293-8.

Raju, IS \& Newman Jr, JC 1979, 'Stress-intensity factors for a wide range of semi-elliptical surface cracks in finite-thickness plates', Engineering Fracture Mechanics, vol. 11, no. 4, pp. 817-29.

Saffih, A \& Hariri, S 2006, 'Numerical study of elliptical cracks in cylinders with a thickness transition', International Journal of Pressure Vessels and Piping, vol. 83, no. 1, pp. 35-41.

Yang, S, Li, C-Q \& Yang, W 2016, 'Analytical model of elastic fracture toughness for steel pipes with internal cracks', Engineering Fracture Mechanics, vol. 153, pp. 50-60.

Zhang, XY, Li, SX, Liang, R \& Akid, R 2013, 'Effect of corrosion pits on fatigue life and crack initiation', paper presented to 13th International Conference on Fracture, Beijing, China. 